\title{
Rosiglitazone Suppresses Calcium Oxalate Crystal Binding and Oxalate-Induced Oxidative Stress in Renal Epithelial Cells by Promoting PPAR- $\gamma$ Activation and Subsequent Regulation of TGF- $\beta 1$ and HGF Expression
}

\author{
Ya-Dong Liu $\mathbb{D}$, Shi-Liang Yu $\mathbb{D}$, Rui Wang, Jian-Nan Liu, Yin-Shan Jin, Yi-Fu Li $\mathbb{D}$, \\ and Rui-Hua An iD \\ Department of Urology, The First Affiliated Hospital of Harbin Medical University, No. 23 You Zheng Street, Harbin, \\ 150001 Heilongjiang, China
}

Correspondence should be addressed to Rui-Hua An; ruihuaan@126.com

Received 15 May 2019; Revised 11 August 2019; Accepted 17 September 2019; Published 12 November 2019

Academic Editor: Alin Ciobica

Copyright (C) 2019 Ya-Dong Liu et al. This is an open access article distributed under the Creative Commons Attribution License, which permits unrestricted use, distribution, and reproduction in any medium, provided the original work is properly cited.

\begin{abstract}
Peroxisome proliferator-activated receptor- (PPAR-) $\gamma$ is a ligand-dependent transcription factor, and it has become evident that PPAR- $\gamma$ agonists have renoprotective effects, but their influence and mechanism during the development of calcium oxalate $(\mathrm{CaOx})$ nephrolithiasis remain unknown. Rosiglitazone (RSG) was used as a representative PPAR- $\gamma$ agonist in our experiments. The expression of transforming growth factor- $\beta 1$ (TGF- $\beta 1$ ), hepatocyte growth factor (HGF), c-Met, p-Met, PPAR- $\gamma, \mathrm{p}-\mathrm{PPAR}-\gamma$ (Ser112), Smad2, Smad3, pSmad2/3, and Smad7 was examined in oxalate-treated Madin-Darby canine kidney (MDCK) cells and a stone-forming rat model. A CCK-8 assay was used to evaluate the effects of RSG on cell viability. In addition, intracellular reactive oxygen species (ROS) levels were monitored, and lipid peroxidation in renal tissue was detected according to superoxide dismutase and malondialdehyde levels. Moreover, the location and extent of $\mathrm{CaOx}$ crystal deposition were evaluated by Pizzolato staining. Our results showed that, both in vitro and in vivo, oxalate impaired PPAR- $\gamma$ expression and phosphorylation, and then accumulative ROS production was observed, accompanied by enhanced TGF- $\beta 1$ and reduced HGF. These phenomena could be reversed by the addition of RSG. RSG also promoted cell viability and proliferation and decreased oxidative stress damage and $\mathrm{CaOx}$ crystal deposition. However, these protective effects of RSG were abrogated by the PPAR- $\gamma$-specific inhibitor GW9662. Our results revealed that the reduction of PPAR- $\gamma$ activity played a critical role in oxalate-induced ROS damage and CaOx stone formation. RSG can regulate TGF- $\beta 1$ and HGF/c-Met through PPAR- $\gamma$ to exert antioxidant effects against hyperoxaluria and alleviate crystal deposition. Therefore, PPAR- $\gamma$ agonists may be expected to be a novel therapy for nephrolithiasis, and this effect is related to PPAR- $\gamma$-dependent suppression of oxidative stress.
\end{abstract}

\section{Introduction}

Emerging data have shown that the incidence and prevalence of nephrolithiasis are increasing remarkably [1]. Approximately $70 \%$ of human kidney stones are primarily composed of calcium oxalate $(\mathrm{CaOx})[2]$. Previous studies have shown that a high concentration of oxalate leads to renal tubular epithelial cell injury and contributes considerably to the deposition and progression of $\mathrm{CaOx}$ crystals [3]. A growing body of evidence suggests that increased $\mathrm{CaOx}$ crystal adhesion to and aggregation in renal tubular cells are associated with the overproduction of reactive oxygen species (ROS) [4]. ROS result in lipid peroxidation of the cellular membranes and serious renal tissue injuries, presumably through oxidative stress [5]. Therefore, antioxidant therapy can attenuate damage caused by renal oxidative stress and prevent $\mathrm{CaOx}$ deposition.

Peroxisome proliferator-activated receptor- $\gamma$ (PPAR- $\gamma$ ), a nuclear hormone receptor, plays central roles in cellular proliferation, morphogenesis, and inflammation as well as the maintenance of cell metabolic homeostasis [5-7]. PPAR- $\gamma$ has also been reported to be highly expressed in 
renal tissues, which are mainly expressed in distal tubules, the inner medullary collecting ducts, and the thick ascending limb of Henle's loop $[8,9]$. It modulates gene expression by binding to peroxisome proliferator response element (PPRE) sites and affects the transcription of downstream target genes [10]. Li et al. demonstrated that the PPAR- $\gamma$ agonist 15 -deoxy- $\Delta 12,14$-prostaglandin J2 (15d-PGJ2) can prevent $\mathrm{CaOx}$ stone formation both in vivo and in vitro [11]. However, the mechanism of PPAR- $\gamma$ signaling in oxalateinduced tubular cell injury requires further investigation.

It is well known that PPAR- $\gamma$ agonists have antioxidant and antifibrosis functions [12-15]. Transforming growth factor- $\beta 1$ (TGF- $\beta 1$ ), as a cytokine with multiple biological functions, plays a prominent role in a variety of kidney diseases, such as glomerulonephritis, renal interstitial fibrosis, and nephrolithiasis $[16,17]$. Oxalate-induced ROS production is considered to be the result of TGF- $\beta 1$ activation [17]. Recently, multiple studies have suggested that PPAR- $\gamma$ agonists can exert a therapeutic effect on kidney disease by inhibiting TGF- $\beta 1$ signal transduction [11]. PPAR- $\gamma$ agonists can inhibit TGF- $\beta 1 \mathrm{mRNA}$ and protein expression [7]. However, it has been confirmed that PPAR- $\gamma$ binds to the putative PPRE in the promoter region of the hepatocyte growth factor (HGF) gene after ligand stimulation and leads to increased HGF gene transcription, mRNA expression, and protein secretion. HGF has been considered a downstream effector of PPAR- $\gamma$ agonists, and some researchers suggest that the antifibrotic activity of PPAR- $\gamma$ agonists is mediated primarily by HGF expression [18]. The HGF/c-Met signal transduction pathway is considered a key regulator of cellular oxidative stress, and exacerbating the activity of this pathway can improve cellular antioxidant capacity [19]. As Imamura et al. reported, the administration of exogenous HGF can attenuate cell-crystal interactions and crystal precipitation in hyperoxaluric rats [20]. Therefore, we hypothesized that PPAR- $\gamma$ serves as a regulator of renal tubular epithelial cell redox status by influencing TGF- $\beta 1$ and HGF. However, there are few studies on the mechanism and effect of PPAR- $\gamma$ agonists in $\mathrm{CaOx}$ models.

PPAR- $\gamma$ agonists include endogenous ligands such as 15d-PGJ2 and synthetic ligands, such as thiazolidinediones (TZDs) $[21,22]$. However, the mechanism of the antilithogenic effects induced by PPAR- $\gamma$ agonists remains unclear. TZDs are highly potent PPAR $-\gamma$ agonists and include rosiglitazone (RSG), pioglitazone (PGZ), and troglitazone (TGZ) [20-22]. RSG is a typical representative PPAR- $\gamma$ agonist and has recently been reported to exert antioxidant effects via a PPAR- $\gamma$-dependent mechanism $[12,22]$. In this study, we used in vitro and in vivo experiments to investigate the alterations in PPAR- $\gamma$ and its downstream effects in a hyperoxaluric environment and to determine whether RSG exerts renal protective effects by regulating TGF- $\beta 1$ and HGF through a PPAR- $\gamma$-dependent signaling pathway.

\section{Materials and Methods}

2.1. Reagents. A canine renal distal tubular epithelium cell line (MDCK) was purchased from the American Type Culture Collection (Rockville, USA). RSG, GW9662, and
PHA665752 were obtained from Sigma-Aldrich (St. Louis, MO, USA). The following primary antibodies were used: p-Met, Smad7, TGF- $\beta 1$, and PPAR- $\gamma$ (Santa Cruz, USA); HGF (Abcam, USA); p-PPAR- $\gamma$ (Ser112) (Bioss, China); c-Met (Proteintech, China); Smad2, Smad3, p-Smad2 3, and Lamin B (Wanleibio, China); and GAPDH (Zhongshan Golden Bridge Bio Co., Ltd., China). The secondary antibodies, including HRP-conjugated AffiniPure goat anti-rabbit IgG and HRP-conjugated AffiniPure goat anti-mouse IgG, were purchased from Zhongshan Golden Bridge Bio Co., Ltd. (Beijing, China). A Nuclear and Cytoplasmic Protein Extraction Kit was acquired from Beyotime Institute of Biotechnology (Shanghai, China).

2.2. Cell Culture. MDCK (CCL34, passages 53 to 90) was cultured in Dulbecco's modified Eagle's medium (DMEM) supplemented with $10 \%$ fetal bovine serum (FBS; Life Technologies) and antibiotics $(100 \mathrm{U} / \mathrm{mL}$ penicillin and $100 \mu \mathrm{g} / \mathrm{mL}$ streptomycin; Life Technologies, Carlsbad, CA, USA) and kept in a humidified atmosphere with $5 \% \mathrm{CO}_{2}$ at $37^{\circ} \mathrm{C}$. Cells were grown to $80 \%-90 \%$ confluence and subcultured by treatment with $0.25 \%$ trypsin and $1 \mathrm{mM}$ ethylenediaminetetraacetic acid (Beyotime Institute of Biotechnology, Shanghai, China). Cells were then coincubated with oxalate (0.5 mM; Sigma-Aldrich), RSG, or GW9662 for 1, 2, and $4 \mathrm{~h}$ at $37^{\circ} \mathrm{C}$ in calcium ion-free minimum essential medium. All experiments were done in triplicate.

2.3. Animal Model and Experimental Design. Sixty male Sprague-Dawley rats weighing 150-200 g were housed in clean plastic cages under controlled temperature $\left(22-25^{\circ} \mathrm{C}\right)$, humidity, and light ( $12 \mathrm{~h}$ light/dark cycle) with free access to food and water. The use of animals and the experimental protocols were reviewed and approved by the Institutional Animal Care and Use Committee, and animals were treated in accordance with the National Institutes of Health Guidelines of Laboratory Animal Care and Use. After a week of adaptation to our experimental animal environment, 60 rats were randomly divided into five groups as follows: (1) control group (standard diet), (2) ethylene glycol (EG) group (calcium oxalate crystal caused by $0.75 \%$ EG administration), (3) RSG group (administered with EG daily and treated with RSG via intragastric administration), (4) GW9662 group (treated with GW9662 via gastric perfusion), and (5) RSG+ GW9662 group (administered with EG and treated with RSG and GW9662 via intragastric administration). Each group consisted of two subgroups of five animals that were treated as above for 7 or 14 days, respectively. On days 7 and 14 after treatment with EG, urine samples were collected for $24 \mathrm{~h}$ period from rats in the metabolic cages and then both rats were anaesthetized. Before sacrificing, the blood was collected from the inferior vena cava for biochemical analysis. The right kidney of each rat was fixed and stored in $4 \%$ paraformaldehyde solution. The left kidneys were frozen immediately in liquid nitrogen and then stored at $-80^{\circ} \mathrm{C}$ before using.

2.4. Cell Viability Assay. To evaluate the effects of RSG on cell viability, a CCK-8 assay was used. MDCK cells were seeded into 96-well culture plates at a density of 8000 cells per well 
and grown for $24 \mathrm{~h}$. Cells were cotreated with various concentrations of RSG $(0,2,4,8,16,32$, and $64 \mu \mathrm{mol} / \mathrm{L})$ and oxalate $(0.5 \mathrm{mM})$ in DMEM medium for 1,2 , and $4 \mathrm{~h}$. At each time point, $10 \mu \mathrm{L}$ of CCK-8 (Dojindo Laboratories, Japan) solutions was added to each well and mixtures were incubated at $37^{\circ} \mathrm{C}$ in an incubator for additional $1 \mathrm{~h}$. The absorbance at $450 \mathrm{~nm}$ was read using a microplate reader (ELx808, BioTek Instruments, Inc., Winooski, VT, USA).

2.5. Measurement of ROS Generation. The level of intracellular ROS induced by oxalate in the presence or absence of RSG and GW9662 was monitored using a dichlorofluorescein diacetate (DCFH-DA) cell-permeant probe (Beyotime Institute of Biotechnology, Shanghai, China). Briefly, the cells from different groups were collected and cultured with $10 \mu \mathrm{mol} / \mathrm{L}$ DCFH-DA at $37^{\circ} \mathrm{C}$ for $20 \mathrm{~min}$ and then rinsed twice with serum-free DMEM to remove the extracellular DCFH-DA. Fluorescence intensities were analyzed at $488 \mathrm{~nm}$ excitation and $525 \mathrm{~nm}$ emission by flow cytometry.

2.6. Transient Transfection. The activity of HGF was silenced by transient transfection of siRNA duplexes against HGF (General Biosystems, Anhui, China) with the assistance of a Lipofectamine 2000 reagent (Invitrogen, Carlsbad, California, USA). Cells were treated with oxalate and RSG at $4 \mathrm{~h}$ posttransfection, and the expression of related proteins was measured by Western blotting. The sequences of the siRNAs are shown in Table S1.

2.7. Renal Oxidative Stress. Lipid peroxidation in whole renal tissue was measured by assaying the malondialdehyde (MDA) content and superoxide dismutase (SOD) enzyme activity according to the manufacturer's protocols (Beyotime Institute of Biotechnology, Shanghai, China) [23].

2.8. Ultrasound. We used color ultrasound to detect whether $\mathrm{CaOx}$ stones had formed in the rat kidneys. This procedure was performed by experienced sonologists who were blinded to the study design.

2.9. Collection and Analysis of Urine and Serum. According to the instructions, creatinine levels in blood and urine were measured with a creatinine assay kit (Wanlei Biological Technology, Shenyang, China). Calcium concentration in urine and serum was measured by an automatic biochemical analyzer (Mindray, China). The content of oxalate in urine is determined by a special detection kit (Trinity Biotech, USA).

2.10. Immunofluorescence (IF). MDCK cells were seeded into 24 -well plates and treated as described above. Briefly, the cells were fixed in $4 \%$ paraformaldehyde for $30 \mathrm{~min}$, washed with PBS three times for $5 \mathrm{~min}$, and then permeabilized with $0.5 \%$ Triton-100 for $60 \mathrm{~min}$. After incubation with primary antibodies overnight at $4^{\circ} \mathrm{C}$, the cells were incubated with secondary antibodies in the dark for $60 \mathrm{~min}$ and then counterstained with a DAPI nuclear stain for $5 \mathrm{~min}$ before images were collected under a fluorescence microscope [24].

2.11. Morphological Staining. Kidney tissues were fixed in a formalin solution and then routinely embedded in paraffin. The specimens were subsequently dehydrated and stained with hematoxylin and eosin ( $\mathrm{H} \& \mathrm{E})$. In addition, $\mathrm{CaOx}$ crystals were identified by Pizzolato staining.

2.12. Immunohistochemistry (IHC). Briefly, paraffinembedded renal tissues $(4 \mu \mathrm{m})$ were immunostained with primary antibodies against $\mathrm{p}-\mathrm{MET}, \mathrm{HGF}$, and TGF- $\beta 1$ according to the manufacturer's instructions. Image capture and quantification of the stained renal tissues were performed using an Olympus BX51 microscope. Positive cells (brown) were counted using Image-Pro plus 6.0 software.

2.13. Western Blot Analysis. MDCK cells exposed to specified concentrations of oxalate and with or without RSG and GW9662 were harvested and homogenized in lysis buffer containing proteinase inhibitors and phosphatase inhibitors (Beyotime Institute of Biotechnology, Shanghai, China). Total protein concentrations of the supernatants were determined with a BCA protein assay (Beyotime Institute of Biotechnology, Shanghai, China). A total of $25 \mu \mathrm{g}$ of protein was separated by $8 \%$ or $10 \%$ SDS-PAGE and electrophoretically transferred onto $0.45 \mu \mathrm{m}$ PVDF membranes. After blocking in $5 \%$ nonfat milk for $1 \mathrm{~h}$ at room temperature, the membranes were incubated with primary antibodies at $4^{\circ} \mathrm{C}$ overnight. The membranes were then incubated with a horseradish peroxidase- (HRP-) conjugated secondary antibody for $1 \mathrm{~h}$ at room temperature. Finally, the protein bands were visualized with an enhanced chemiluminescence (ECL) Western blotting reagent. The blots were analyzed using Bio-Rad image analysis software, and the results are representative of at least three independent experiments. Proteins from samples from patients with urolithiasis and mice were extracted and homogenized with a homogenizer, and the subsequent steps were the same as above.

2.14. Statistical Analysis. Each experiment was performed three times, and all data are expressed as the means \pm SD. ANOVA was used to analyze the differences among multiple groups, and a two-tailed $t$-test was used to compare two groups. Values of $p<0.05$ were considered to indicate a statistically significant difference.

\section{Results}

3.1. RSG Promoted the Viability and Proliferation of MDCK Cells Exposed to Oxalate. To determine the effect of RSG on kidney epithelial cells (MDCK cells) treated with oxalate, their viability and proliferation were measured by CCK- 8 assays. Consistent with our previous findings, MDCK cell exposure to oxalate led to a prominent concentrationdependent suppression of cell viability. Compared to that in the control group, cell viability was significantly decreased at oxalate concentrations greater than $0.5 \mathrm{mM}$ (data not shown).

As shown in Figure 1(a), RSG is not toxic to cells at a range of concentrations. However, RSG inhibited cell viability distinctly at concentrations greater than $8 \mu \mathrm{mol} / \mathrm{L}$. To determine the function of RSG in oxalate-induced MDCK cell injury, we treated MDCK cells with gradient concentrations of RSG and $0.5 \mathrm{mM}$ oxalate for 1,2 , or $4 \mathrm{~h}$. Importantly, peak protection occurred after exposure to an RSG concentration of $4 \mu \mathrm{M}$ for 2 and $4 \mathrm{~h}$; nevertheless, treatment with 

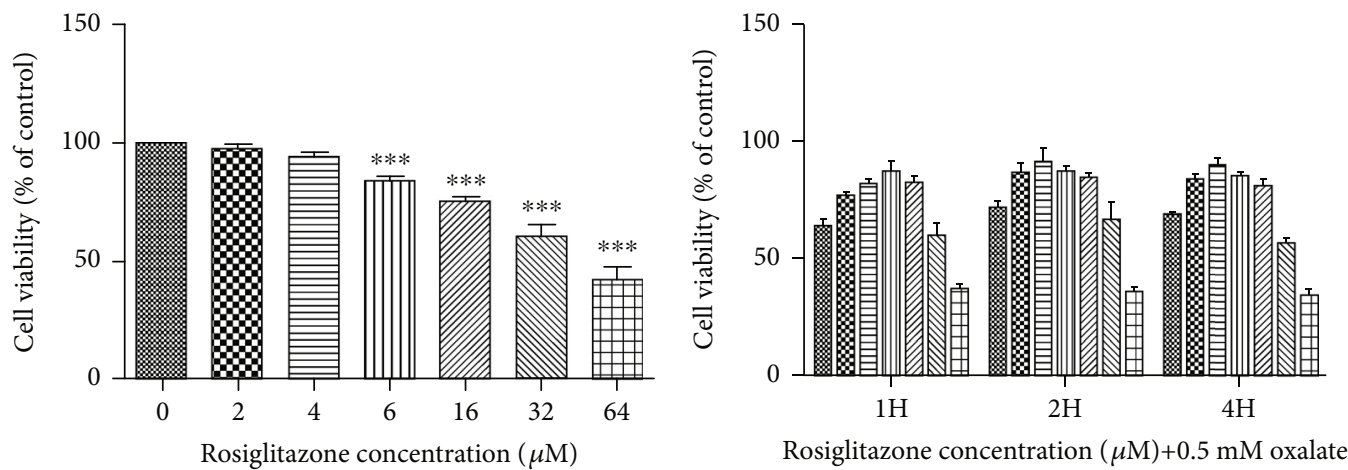

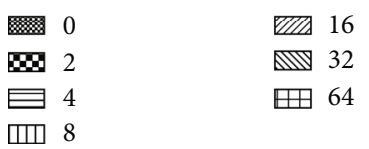

(a)

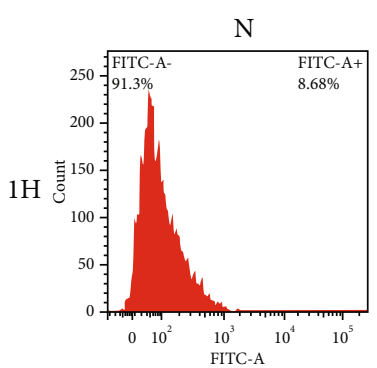

$2 \mathrm{H}$

$4 \mathrm{H}$
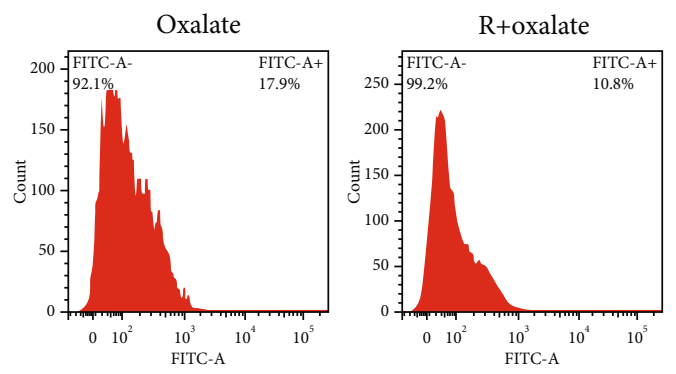

$\begin{array}{ll}\text { 자자 } & 0 \\ 00 & 2 \\ \text { E } & 4 \\ \text { एव } & 8\end{array}$

16

32

\# 64

(b)
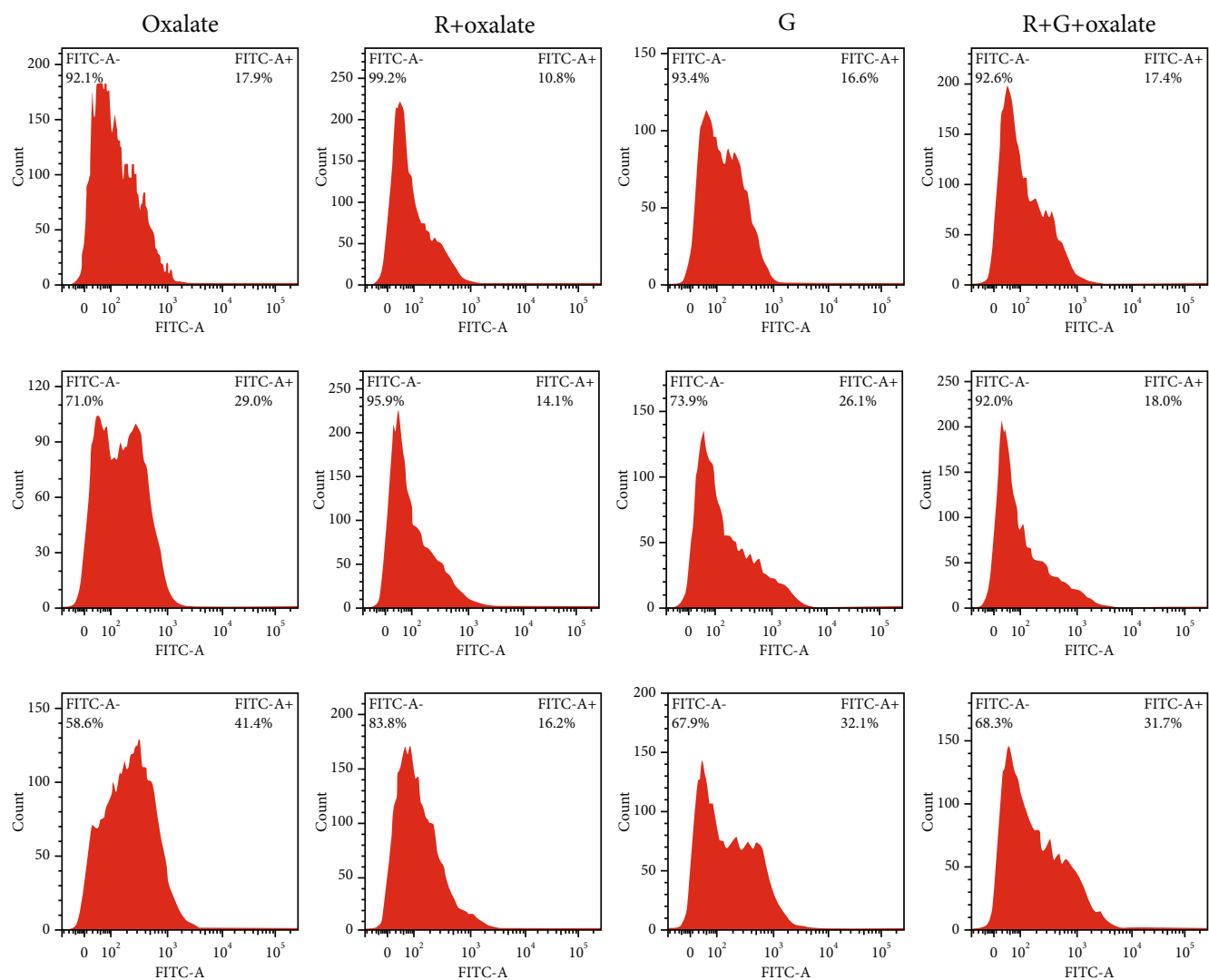

(c)

Figure 1: Continued. 


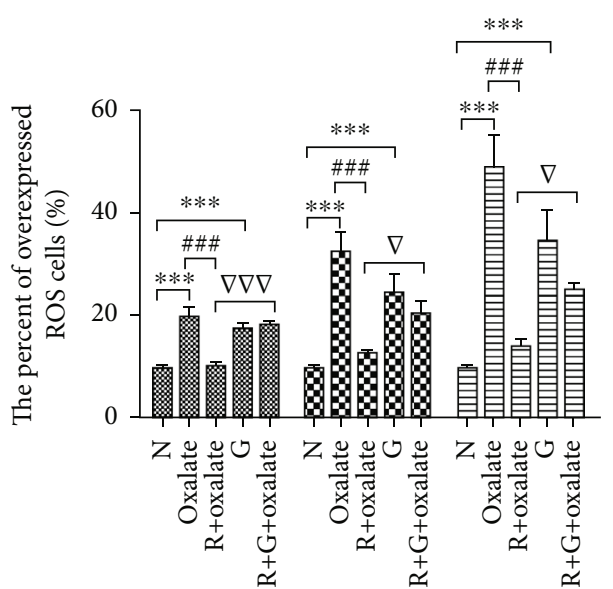

(d)

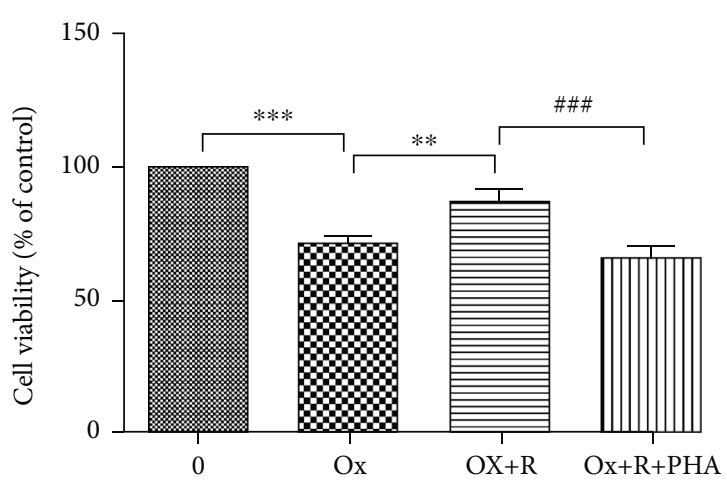

(e)

FIGURE 1: Rosiglitazone (RSG) promoted the viability of MDCK cells. (a) MDCK cells were treated with a concentration gradient of RSG. (b) Cells were cotreated with various concentrations of RSG $(0,2,4,8,16,32$, and $64 \mu \mathrm{mol} / \mathrm{L})$ and oxalate $(0.5 \mathrm{mM})$ in DMEM medium for 1,2 , and $4 \mathrm{~h}$, and a CCK-8 assay was performed to assess cell viability. (c) The generation of ROS was detected by a DCFH-DA assay. (d) Percent of ROS overexpressing cells per group. (e) Viability of MDCK cells treated with RSG, oxalate, and PHA665752. The data shown are representative of at least three independent experiments. N: normal; G: GW9662; H: hour; PHA: PHA665752. ${ }^{*} p<0.05,{ }^{* *} p<0.01$, and ${ }^{* * *} p<0.001$ versus the control group; ${ }^{\#} p<0.05,{ }^{\# \#} p<0.01$, and ${ }^{\# \# \#} p<0.001$ versus the $0.5 \mathrm{mM}$ oxalate group; $\nabla^{*} p<0.05, \nabla \nabla p<0.01$, and $\nabla \nabla<0.001$ versus the RSG-treated group.

$5 \mu \mathrm{M}$ or higher RSG for $2 \mathrm{~h}$ significantly inhibited MDCK cell viability, as presented in Figure 1(b). Therefore, incubation with $4 \mu \mathrm{M}$ RSG and $0.5 \mathrm{mM}$ oxalate for $2 \mathrm{~h}$ was used as the treatment condition in the subsequent experiments.

3.2. RSG Provides Protection against Oxalate-Induced Oxidative Damage to MDCK Cells. Cumulative evidence has demonstrated that oxidative stress is closely related to oxalate-induced renal epithelial cell damage. To assess whether RSG protects MDCK cells from oxidative stress induced by sodium oxalate treatment for different durations (1, 2, and $4 \mathrm{~h}$ ), intracellular ROS were visualized by flow cytometry, which measured the generation of fluorescent 2,7-dichlorofluorescein diacetate (DCFH-DA) in MDCK cells. As shown in Figure 1(c), ROS generation in response to oxalate was significantly increased versus that in untreated controls in a concentration- and time-dependent manner. However, ROS generation was markedly blunted compared to that in the oxalate-treated group in the presence of RSG $(p<0.05)$. In addition, the PPAR- $\gamma$ inhibitor GW9662, PHA665752 (c-Met inhibitor), and siRNA silencing of HGF markedly abolished the protective effect of RSG (Figures 1(e), 2(e), and 2(f)). Considering the effect of siRNA knockdown of HGF, RNAil was selected for knockout in subsequent experiments (Figure 2(d)).

3.3. The Effect of RSG on PPAR- $\gamma$ Expression. To explore the mechanism by which RSG exerts renal protection, we first examined the influence of oxalate on PPAR- $\gamma$ and p-PPAR$\gamma$ (Ser112) expression. Our data have shown that the expression of PPAR- $\gamma$ and P-PPAR- $\gamma$ (Ser112) was detected in renal epithelial cells both in vitro and in vivo. However, oxalate treatment could result in a decrease in PPAR- $\gamma$ expression in both the nucleus and cytoplasm in MDCK cells.
PPAR- $\gamma$ and p-PPAR- $\gamma$ (Ser112) were also decreased in the EG group compared with the normal group. In contrast to oxalate-treated cells, the expression of the PPAR $-\gamma$ protein increased in the presence of RSG in both the nucleus and cytoplasm in MDCK cells, and increased PPAR- $\gamma$ and p-PPAR- $\gamma$ (Ser112) expression was also observed in vivo. In addition, the PPAR- $\gamma$ inhibitor GW9662 could simulate the effect of oxalate on PPAR- $\gamma$ expression (Figures 2(a), 3(a), 4(d), and 4(g); Figures S1 and S2).

3.4. The Effect of RSG on HGF/c-Met and the TGF- $\beta 1 /$ Smad Pathway. PPAR- $\gamma$ is upstream of the HGF/c-Met signaling pathway and can regulate the activation of Smad7; therefore, we determined whether PPAR- $\gamma$ regulates the expression of HGF, c-Met, and Smad7 in renal tubular epithelial cells during kidney stone formation. Western blotting, IF, and IHC were used to determine the expression of HGF, c-Met, Smad7, and PPAR- $\gamma$. As shown in Figures 2-5, compared to that in the oxalate groups, the expression of HGF, p-Met, and Smad7 was upregulated in the RSG treatment groups. However, we found that cotreatment with GW9962, an effective PPAR- $\gamma$ inhibitor, significantly reversed the overexpression of HGF, p-Met, and Smad7. Furthermore, compared to that in the control group, the expression of TGF- $\beta 1$ and phosphorylated Smad2 3 increased in a time-dependent manner in the groups induced with either oxalate or EG. In contrast, in both animal and cell experiments, the expression of the abovementioned proteins was conspicuously reduced in a time-dependent manner in response to RSG.

3.5. Assessment of Renal Function and Calcium and Oxalate Metabolism. To verify the protective effect of RSG on renal function and calcium and oxalate metabolism, the contents of creatinine, calcium, and oxalate in the urine and serum 


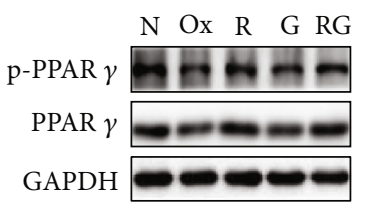

$1 \mathrm{H}$

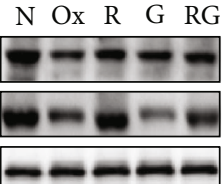

$2 \mathrm{H}$

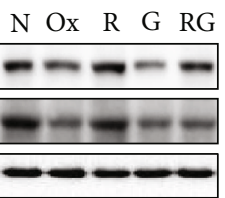

$4 \mathrm{H}$

(a)

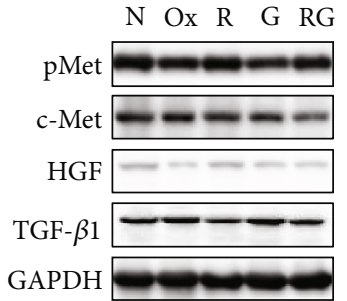

$1 \mathrm{H}$

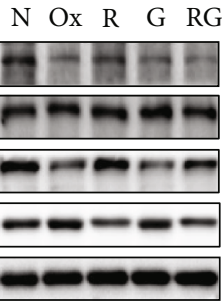

$2 \mathrm{H}$

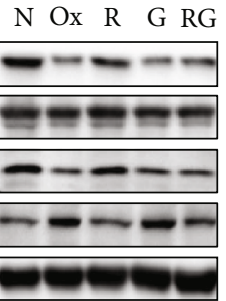

$4 \mathrm{H}$

(b)

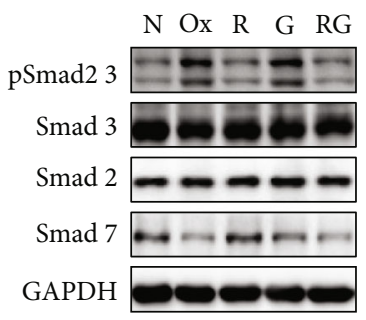

$1 \mathrm{H}$

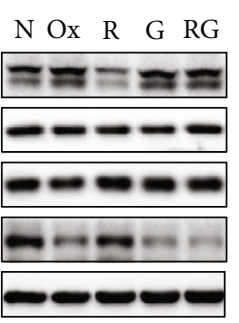

$2 \mathrm{H}$

N Ox R G RG

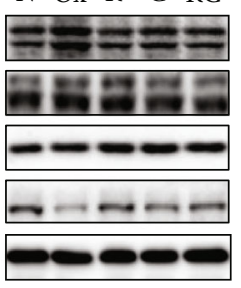

$4 \mathrm{H}$

(c)

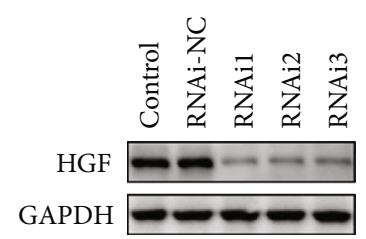

(d)
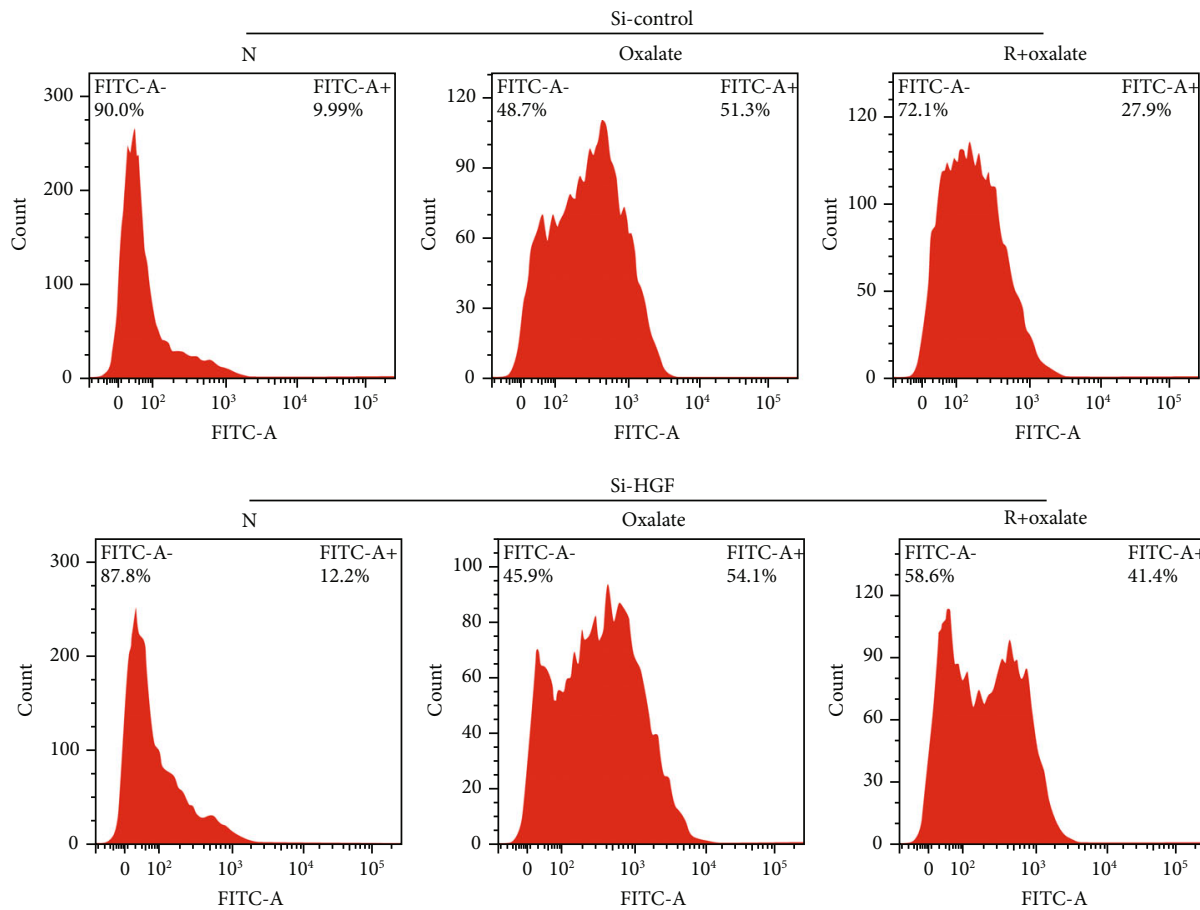
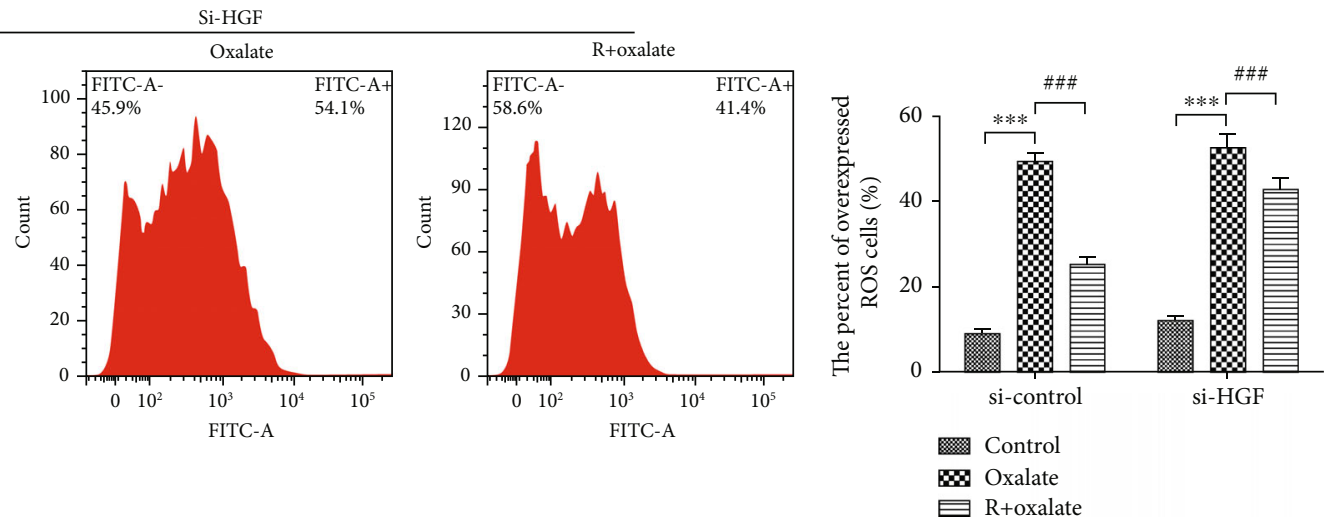

(f)

FIGURE 2: RSG promoted the activity of MDCK cells by inhibiting TGF- $\beta 1 /$ Smad and activating the HGF/c-Met pathway. (a-c) Protein expression levels of TGF- $\beta 1$, HGF, c-Met, p-Met, PPAR- $\gamma$, p-PPAR- $\gamma$, Smad7, Smad2, Smad3, and pSmad2 3 were analyzed using Western blotting after treatment for 1, 2, and 4 hours. The relative protein levels were normalized to the GAPDH level. (d) Western blot assay of HGF after siRNA transfection. (e, f) siRNA-mediated knockdown of HGF led to significant inhibition of the antioxidant capacity of RSG. The quantitative results are expressed as the means \pm SD of three experiments. N: normal; Ox: oxalate; R: rosiglitazone; G: GW9662; H: hour. ${ }^{* * *} p<0.001$ versus the control group; ${ }^{\# \#} p<0.001$ versus the $0.5 \mathrm{mM}$ oxalate group.

were measured on days 7 and 14. As shown in Tables 1 and 2, compared with those in the normal group, creatinine and oxalate levels in the EG group increased tremendously at 7 and 14 days $(p<0.001)$, while RSG treatment signifi- cantly ameliorated renal function damage caused by $\mathrm{CaOx}$ crystals and reduced the increase of oxalate. However, the addition of GW9662 could inhibit the renal protective effect of RSG. In addition, the calcium concentration in the serum 


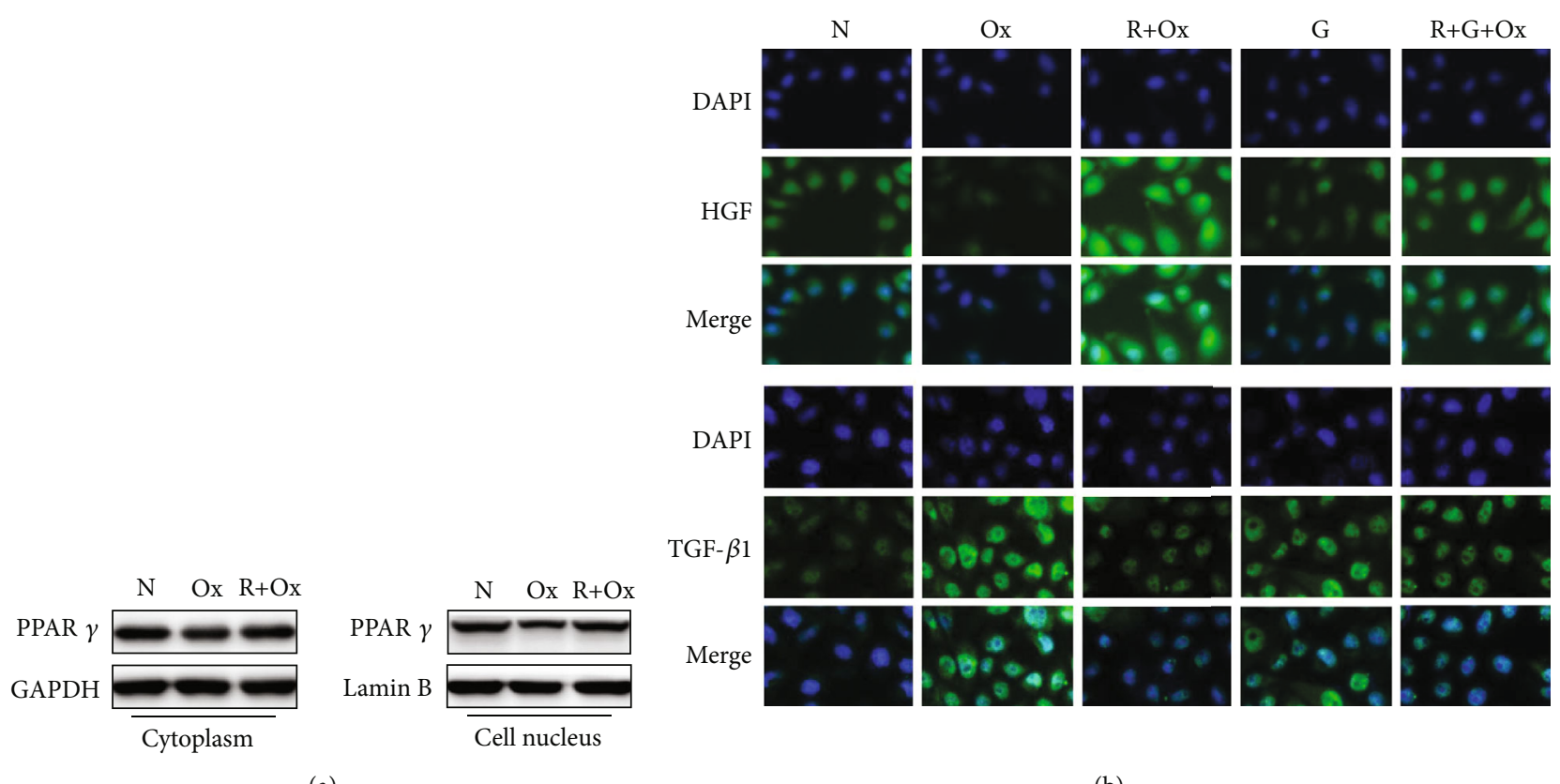

(a)

(b)

Figure 3: (a) The expression of PPAR- $\gamma$ in cytoplasm and nucleus was detected by Western blotting in vitro. (b) Representative fluorescence images of HGF and TGF- $\beta 1$ expression were evaluated $(\times 200)$. N: normal; Ox: oxalate; R: rosiglitazone; G: GW9662.

and urine of the EG group was higher than that in the normal group, and there was no significant difference among the other groups.

3.6. RSG Attenuated EG-Induced Oxidative Stress In Vivo. To further evaluate the role of RSG in antioxidant stress in animal experiments, SOD and MDA were measured to determine the level of lipid peroxidation. As presented in Figure 4(c), the SOD level was significantly higher in the EG+RSG treatment group than in the EG treatment group on days 7 and 14. In contrast, compared to the control conditions, exposing the kidney tissues to EG dramatically blunted SOD activity in a dose-dependent manner. In addition, no remarkable variation was observed in the SOD levels between the EG+RSG+GW9662 group and the RSG+EG group on day 7. However, as shown in Figure 4(b), compared to the SOD activity, the MDA levels showed opposite effects in the corresponding groups.

3.7. RSG Markedly Ameliorated the Deposition of $\mathrm{CaOx}$ Crystals and EG-Induced Histopathological Morphological Alterations in the Rat Model. To determine whether RSG could suppress the formation of kidney stones, Pizzolato staining and color Doppler ultrasound were performed to observe the formation of renal crystal deposits. Crystal deposits were clearly observed in the distal renal tubule at the junction of the renal cortex and medulla (Figure 6(a); Figure S3). The representative images showing crystallization in the kidneys are consistent with the color ultrasound images, as illustrated in Figure 4(a). Compared to EG treatment alone, RSG resulted in a significant reduction in the retention of $\mathrm{CaOx}$ crystals. Histopathologic examination revealed evident atrophy of glomeruli and renal tubular epithelial cell swelling and deformation in EG-treated rats. However, the characteristic morphological changes of hyperoxaluric rats in the presence of RSG were significantly attenuated (Figure S4). The degree and quantity of dark, dense $\mathrm{CaOx}$ crystals increased substantially over time in the EG-only group, and this increase was significantly reduced after RSG injection. However, the potential antinephrolithic role of RSG was reversed by GW9662 administration, and no positive staining areas were found for the control group or the GW9662 treatment group after microscopic observation.

\section{Discussion}

The present study demonstrates the significant role of the PPAR- $\gamma$-HGF/c-Met and PPAR- $\gamma$-TGF- $\beta 1 /$ Smad pathways in both in vivo and in vitro $\mathrm{CaOx}$ nephrolithiasis models. Oxidative stress plays a critical role in the pathogenesis of $\mathrm{CaOx}$ nephrolithiasis [25]. We found that oxalate antagonized the expression and activity of PPAR- $\gamma$ and promoted ROS by increasing TGF- $\beta 1 /$ Smad signaling and decreasing HGF/c-Met signaling. Moreover, we provide evidence that RSG, a direct target of PPAR- $\gamma$, suppresses oxalate-induced ROS by inactivating the TGF- $\beta 1 /$ Smad signaling pathway and activating the HGF/c-Met signaling pathway. Collectively, the current results implicate the decreasing expression and activity of PPAR- $\gamma$ as mechanisms that initiate $\mathrm{CaOx}$ nephrolithiasis. Taken together, our data suggest that PPAR- $\gamma$ activation could be an effective method to protect against oxalate-mediated ROS by enhancing HGF/c-Met signaling and suppressing TGF- $\beta 1 / \mathrm{Smad}$ signaling in renal tubular cells (Figure 7). 

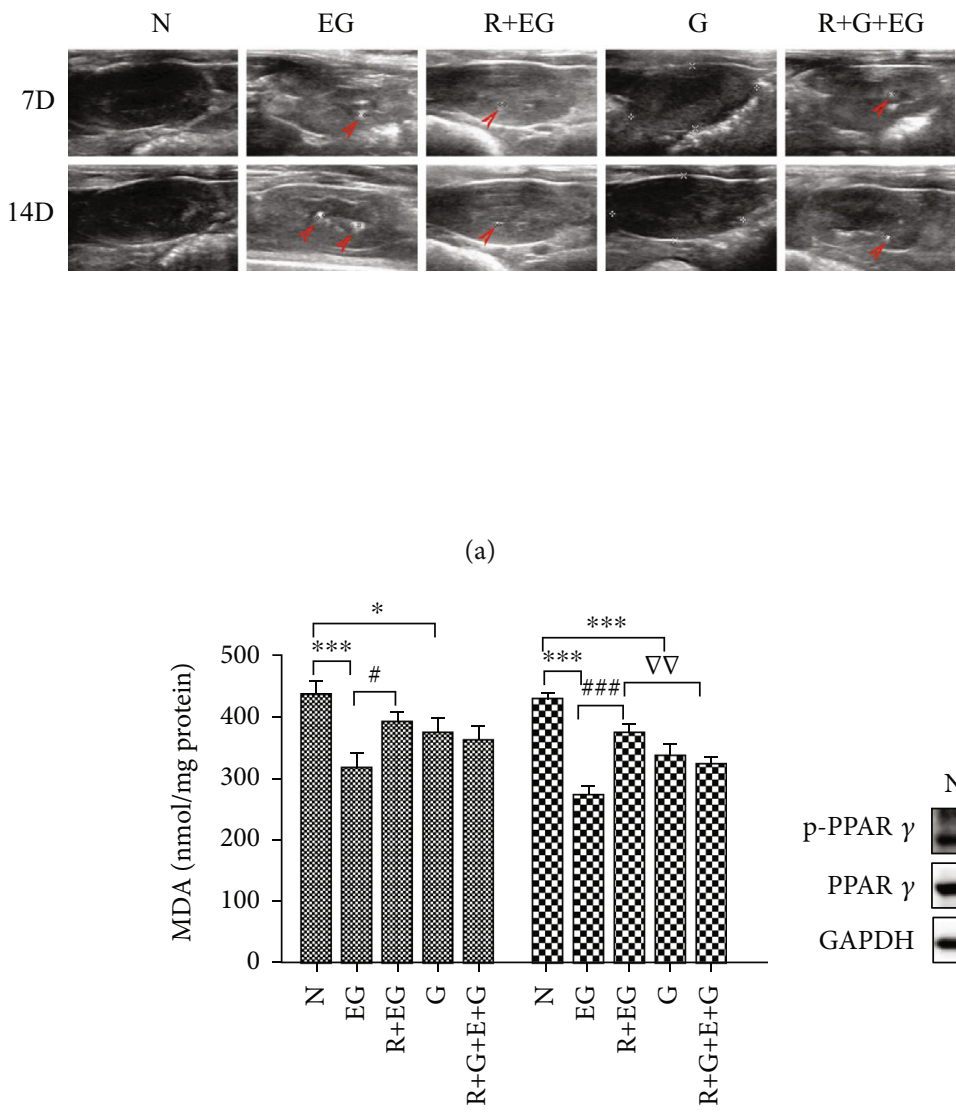

$7 \mathrm{D}$

(\$14D

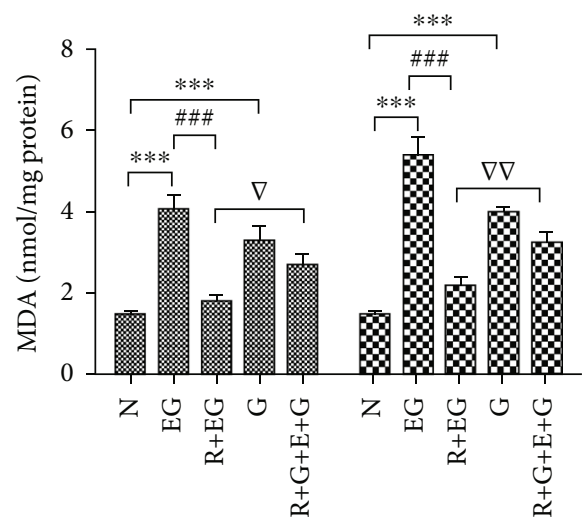

7D

$\otimes 14 \mathrm{D}$

(b)

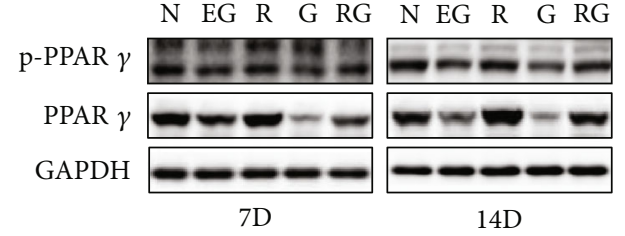

(d)

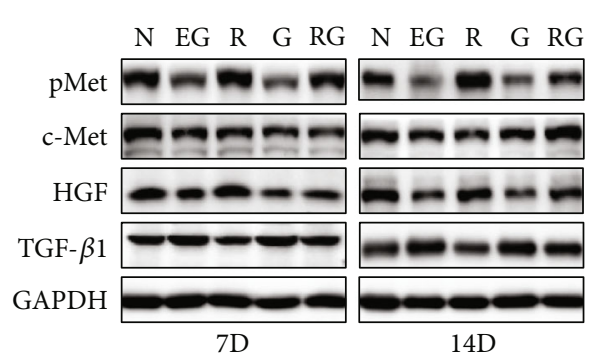

(e)

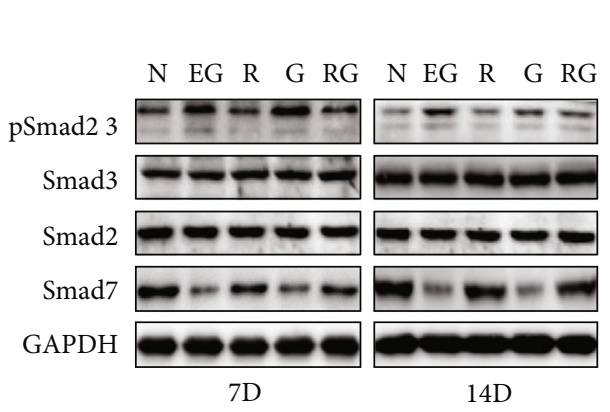

(f)

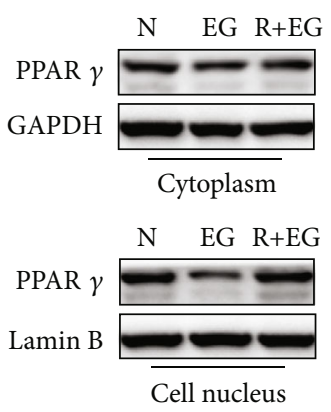

(g)

FIgURE 4: (a) The formation of calcium oxalate crystals in different groups was observed by color Doppler ultrasound (red arrow indicates the stone). (b, c) Effect of RSG on the MDA level and SOD activity in renal tissue on days 7 and 14, respectively. (d-f) Protein expression in vivo was detected by Western blotting. (g) The expression of PPAR- $\gamma$ in cytoplasm and nucleus was detected by Western blotting in vivo. The data shown are representative of at least three independent experiments. N: normal; EG: ethylene glycol; R: rosiglitazone; G: GW9662; D: day. ${ }^{*} p<0.05$ and ${ }^{* * *} p<0.001$ versus the control group; ${ }^{\#} p<0.05$ and ${ }^{\# \# \#} p<0.001$ versus EG group; $\nabla p<0.05$ and $\nabla \nabla p<0.01$ versus the RSG-treated group.

In the kidney, PPAR- $\gamma$ is mainly selectively expressed in the medullary collecting ducts and pelvic urothelium and is significant in the pathogenesis of many kinds of kidney diseases [26]. However, the effect of oxalate on PPAR- $\gamma$ expres- sion and activity and the downstream consequences have not been defined in renal tubular epithelial cells. We found that oxalate targets PPAR- $\gamma$ and promotes ROS production in tubular epithelial cells and a rat model. Our results 

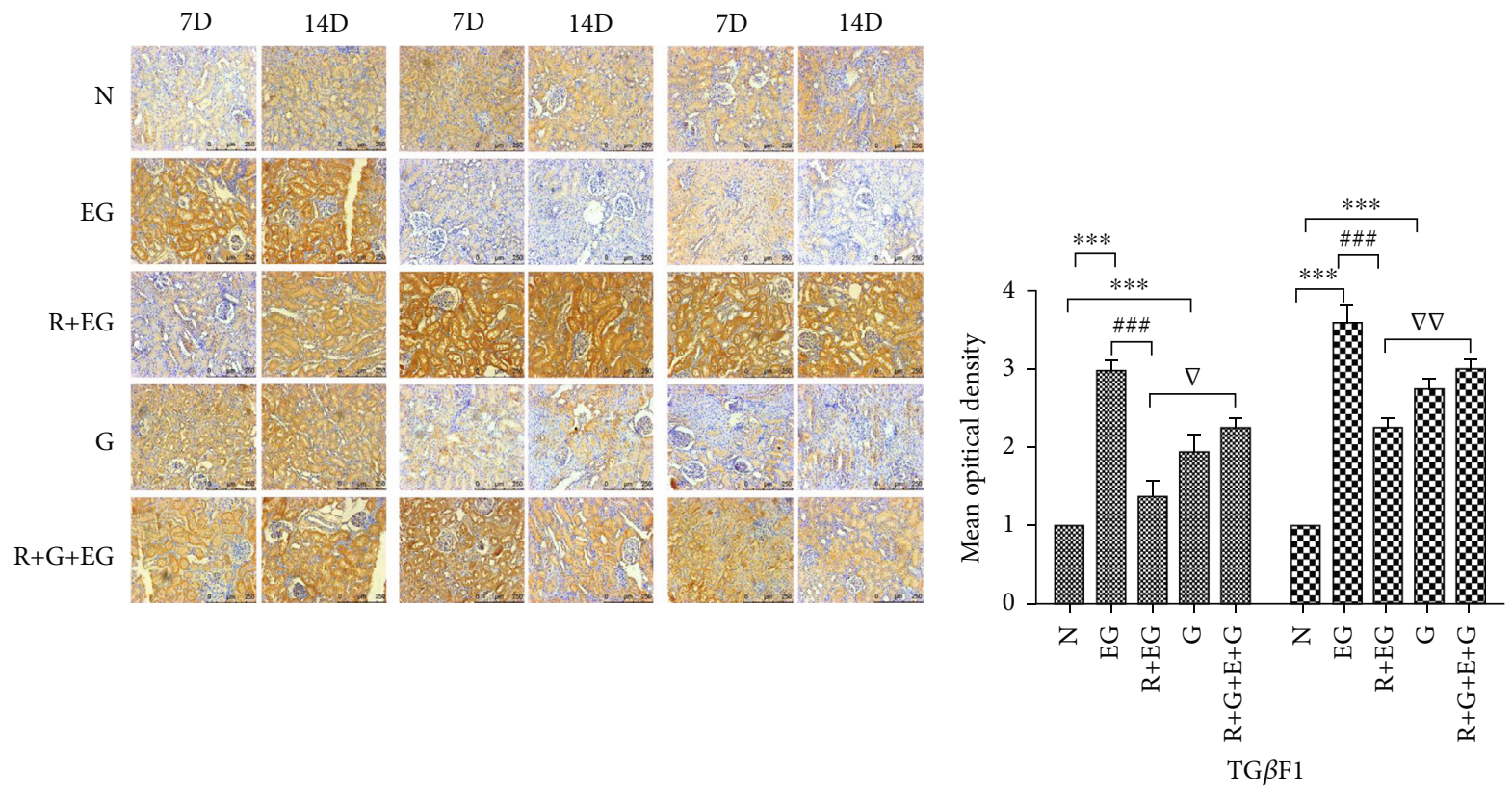

$7 \mathrm{D}$

\$ 14D

(a)

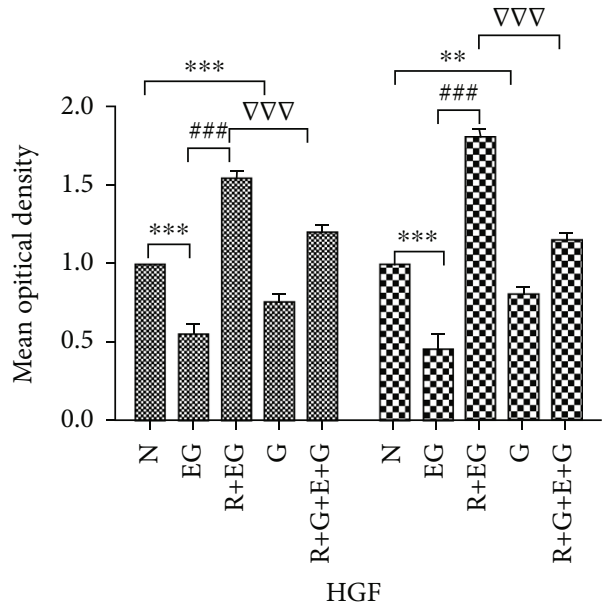

$7 \mathrm{D}$

14D

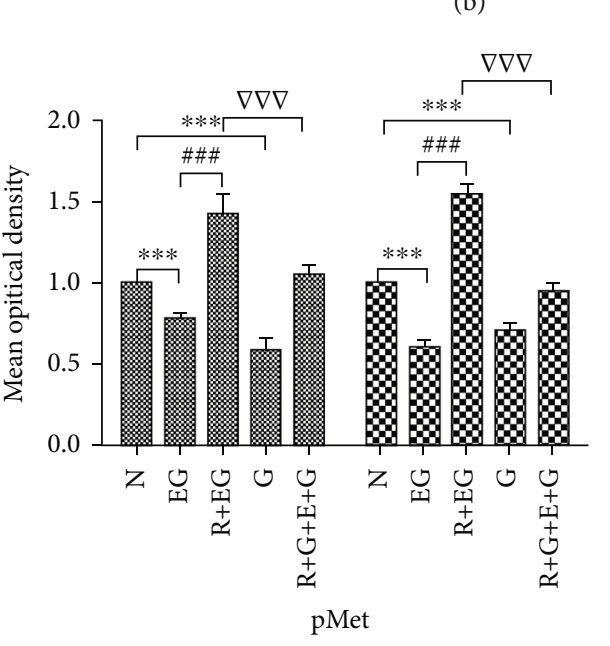

$7 \mathrm{D}$

BD 14D

(c)

(d)

FIGURE 5: Representative immunohistochemistry images of kidney tissues. (a) Level of TGF- $\beta 1$ was decreased in the RSG-treated group, while accumulation of HGF and p-Met by IHC staining in the RSG group was higher than that in the EG-induced rat model $(\times 200)$. (b-d) Immunohistochemical expressions of TGF- $\beta 1$, HGF, and p-Met were evaluated by densitometric analysis. The quantitative results are expressed as the means \pm SD of three experiments. N: normal; EG: ethylene glycol; R: rosiglitazone; G: GW9662; D: day. ${ }^{*} p<0.05$, ${ }^{* *} p<0.01$, and ${ }^{* * *} p<0.001$ versus the control group; ${ }^{\# \#} p<0.001$ versus EG group; ${ }^{\nabla} p<0.05,{ }^{\nabla \nabla} p<0.01$, and $\nabla \nabla \nabla p<0.001$ versus the RSG-treated group.

demonstrate that PPAR- $\gamma$ is present in tubular cells and is downregulated upon oxalate treatment. Oxalate inhibits not only PPAR- $\gamma$ expression but also phosphorylation, which indicates PPAR- $\gamma$ activity. Our results are consistent with some reports demonstrating that in animal models of diabetes, PPAR- $\gamma$ mRNA and protein levels are significantly reduced, while superoxide radical levels are increased [27,
28]. Administration of the PPAR- $\gamma$ antagonist GW9662 has been shown to increase ROS concentrations in some cell types [29]. These findings provide evidence that PPAR $-\gamma$ is a critical intermediate modulator that is beneficial in reducing oxidative stress. The PPAR- $\gamma$ agonist RSG has been reported to have anti-inflammatory and antioxidative effects. We found that RSG treatment suppressed ROS production 
TABLE 1: Comparison of the contents of creatinine among groups.

\begin{tabular}{|c|c|c|c|c|c|}
\hline & $\mathrm{N}$ & EG & $\mathrm{R}+\mathrm{EG}$ & G & $\mathrm{R}+\mathrm{G}+\mathrm{EG}$ \\
\hline \multicolumn{6}{|l|}{ Serum $7 D$} \\
\hline Creatinine $(\mathrm{mg} / \mathrm{dL})$ & $1.48 \pm 0.02$ & $1.94 \pm 0.07^{\mathrm{a} * * *}$ & $1.70 \pm 0.05^{\mathrm{b} * *}$ & $1.58 \pm 0.01$ & $1.76 \pm 0.03$ \\
\hline \multicolumn{6}{|l|}{ Serum $14 D$} \\
\hline Creatinine $(\mathrm{mg} / \mathrm{dL})$ & $1.55 \pm 0.71$ & $2.36 \pm 0.04^{\mathrm{a} * * *}$ & $1.66 \pm 0.10^{\mathrm{b} * * *}$ & $1.58 \pm 0.06$ & $2.00 \pm 0.05^{\mathcal{C} * * *}$ \\
\hline \multicolumn{6}{|l|}{ Urine $7 D$} \\
\hline Creatinine $(\mathrm{mg} / \mathrm{dL})$ & $102.34 \pm 5.20$ & $143.15 \pm 1.30^{\mathrm{a} * * *}$ & $125.05 \pm 4.83^{\mathrm{b} * *}$ & $110.78 \pm 0.44$ & $129.21 \pm 4.55$ \\
\hline \multicolumn{6}{|l|}{ Urine $14 D$} \\
\hline Creatinine $(\mathrm{mg} / \mathrm{dL})$ & $107.67 \pm 7.35$ & $223.12 \pm 7.96^{\mathrm{a} * * *}$ & $167.60 \pm 6.86^{\mathrm{b} * * *}$ & $136.12 \pm 8.99^{\mathrm{a} *}$ & $196.85 \pm 8.99^{\mathrm{C} *}$ \\
\hline
\end{tabular}

${ }^{a * * *} p<0.001$ versus the control group; ${ }^{b_{* *}} p<0.01$ and ${ }^{b_{* * *}} p<0.001$ versus EG group; ${ }^{c_{*}} p<0.01$ and ${ }^{c_{* * *}} p<0.001$ versus the RSG-treated group.

TABLE 2: Comparison of calcium and oxalate metabolism levels among groups.

\begin{tabular}{|c|c|c|c|c|c|}
\hline & $\mathrm{N}$ & EG & $\mathrm{R}+\mathrm{EG}$ & G & $\mathrm{R}+\mathrm{G}+\mathrm{EG}$ \\
\hline \multicolumn{6}{|l|}{ Serum 7D } \\
\hline $\mathrm{Ca}(\mathrm{mmol} / \mathrm{L})$ & $2.42 \pm 0.03$ & $2.50 \pm 0.03^{\mathrm{a} *}$ & $2.46 \pm 0.01$ & $2.43 \pm 0.02$ & $2.48 \pm 0.02$ \\
\hline \multicolumn{6}{|l|}{ Serum 14D } \\
\hline $\mathrm{Ca}(\mathrm{mmol} / \mathrm{L})$ & $2.41 \pm 0.03$ & $2.51 \pm 0.02^{\mathrm{a} *}$ & $2.45 \pm 0.02$ & $2.42 \pm 0.02$ & $2.46 \pm 0.02$ \\
\hline \multicolumn{6}{|l|}{ Urine $7 D$} \\
\hline $\mathrm{Ca}$ (mg/day) & $2.50 \pm 0.03$ & $2.59 \pm 0.02^{\mathrm{a} *}$ & $2.56 \pm 0.02$ & $2.45 \pm 0.02$ & $2.57 \pm 0.01$ \\
\hline \multicolumn{6}{|l|}{ Urine $14 D$} \\
\hline $\mathrm{Ca}$ (mg/day) & $2.49 \pm 0.01$ & $2.62 \pm 0.03^{\mathrm{a} * * *}$ & $2.57 \pm 0.03$ & $2.46 \pm 0.01$ & $2.61 \pm 0.02$ \\
\hline \multicolumn{6}{|l|}{ Urine $7 D$} \\
\hline Oxalate (mg/day) & $1.54 \pm 0.04$ & $4.27 \pm 0.21^{\mathrm{a} * * *}$ & $3.05 \pm 0.22^{\mathrm{b} * * *}$ & $1.57 \pm 0.03$ & $3.63 \pm 0.21^{\mathrm{c} * * *}$ \\
\hline \multicolumn{6}{|l|}{ Urine $14 D$} \\
\hline Oxalate (mg/day) & $1.56 \pm 0.03$ & $8.33 \pm 0.29^{\mathrm{a} * * *}$ & $5.01 \pm 0.19^{\mathrm{b} * * *}$ & $1.56 \pm 0.03$ & $5.75 \pm 0.20^{\mathrm{C} * * *}$ \\
\hline
\end{tabular}

${ }^{a_{*}} p<0.05$ and ${ }^{a_{* * *}} p<0.001$ versus the control group; ${ }^{b_{* * *}} p<0.001$ versus EG group; ${ }^{c_{* * *}} p<0.001$ versus the RSG-treated group.

both in vitro and in vivo. These results are in accordance with some reports suggesting that the PPAR- $\gamma$ agonist PGZ suppressed renal crystal formation as well as acute renal injury by attenuating oxidative stress, apoptosis, and inflammatory response in rat models [25]. To further elucidate the important role of PPAR- $\gamma$, we inhibited PPAR- $\gamma$ using GW9662. Our results showed that GW9662 significantly inhibited PPAR- $\gamma$ expression and increased intracellular ROS levels. Thus, our current study demonstrates that oxalate increases ROS levels by suppressing PPAR- $\gamma$ in tubular epithelial cells and that GW9662 completely blocks the protective effect of RSG, which indicates that RSG plays a protective role by activating PPAR- $\gamma$.

Oxalate-induced molecular changes are a major contributor to ROS production and the development of $\mathrm{CaOx}$ nephrolithiasis [30]. PPAR- $\gamma$ has thus become a therapeutic target for diabetic nephropathy, hypertensive nephropathy, glomerulonephritis, and other chronic kidney diseases $[5,28]$. PPAR $-\gamma$ agonists have been increasingly recognized as possessing potent antifibrotic activity and antioxidative effects that effectively prevent renal dysfunction resulting from chronic kidney diseases [21]. Treatment with the PPAR- $\gamma$ agonist PGZ can relieve oxidative stress and exert nephroprotective effects against cisplatin-induced renal damage [31]. Our experiment clearly shows that RSG can effectively inhibit increases in MDA concentrations and decreases in SOD levels in a hyperoxaluric rat model. In an in vitro experiment, we also observed that RSG significantly alleviated the oxalate-induced ROS level increase in MDCK cells and that RSG effectively suppressed renal crystal formation in the rat model. In addition, as some ligands of PPAR- $\gamma$ have functions independent of PPAR- $\gamma$, we used GW9662 to test whether the effect of RSG is PPAR- $\gamma$ dependent [32]. We found that GW9662 nearly completely blocks the protective effect of RSG, which indicates that RSG plays a protective role by activating PPAR- $\gamma$. Similar results were obtained using other PPAR agonists, such as PGZ, TGZ, and 15d-PGJ2. Thus, we found that PPAR $-\gamma$ activation plays an important role in both hyperoxaluria-induced renal injury in vivo and in oxalate-induced cellular ROS accumulation in MDCK cell cultures in vitro.

Although our above findings demonstrated that PPAR- $\gamma$ plays a critical role in maintaining redox status, the downstream consequences of PPAR- $\gamma$ in the presence of oxalate have not been explored. The major finding of this study is that endothelial PPAR- $\gamma$ protects tubular cells from ROS 

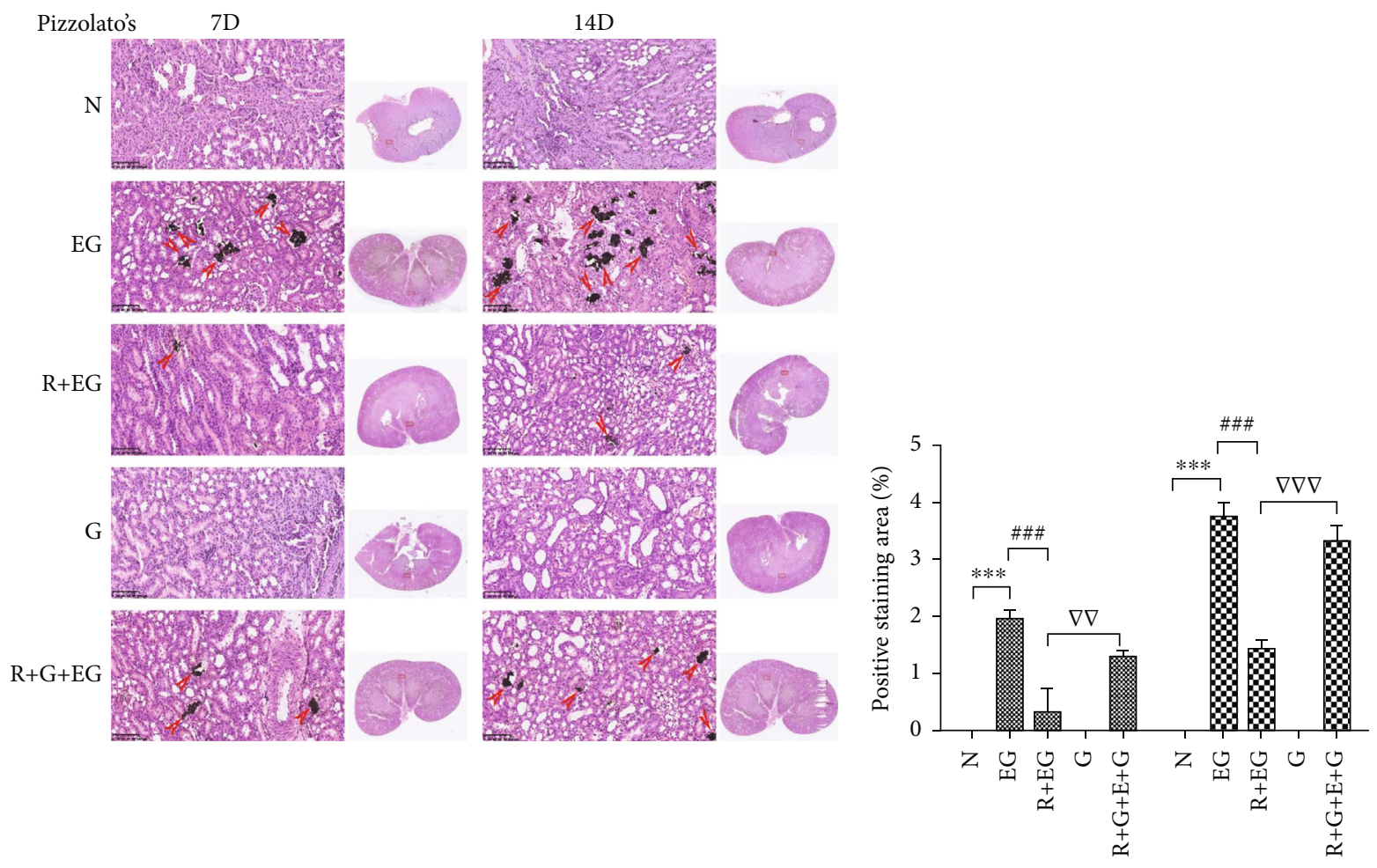

7D

B. $14 \mathrm{D}$

(a)

(b)

Figure 6: (a) Pizzolato's method was performed to observe the formation of renal crystal deposits at the 7th day and 14th day time points $(\times 200)$. (b) The semiquantitative analysis bar graph was used to evaluate the deposition of CaOx. Each value represents the mean \pm SD for triplicate samples. The red arrows indicate CaOx crystals. N: normal; EG: ethylene glycol; R: rosiglitazone; G: GW9662; D: day. ${ }^{* *} p<0.001$ versus the control group; ${ }^{\# \# \#} p<0.001$ versus the EG group; $\nabla p<0.05$ and $\nabla \nabla \nabla p<0.001$ versus the RSG-treated group.

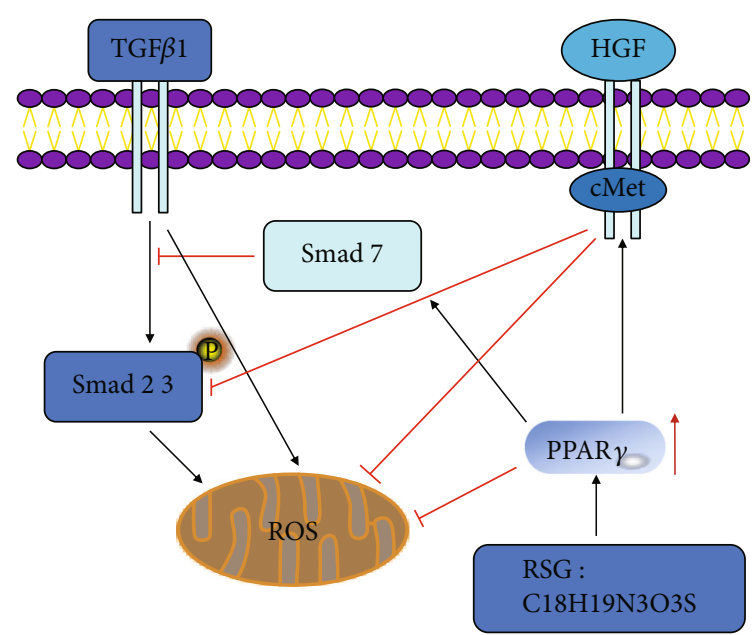

FIGURE 7: Diagram illustrating the signaling pathways involved in RSG inhibiting the formation of kidney stones.

damage by regulating the balance of TGF- $\beta 1 /$ Smad and $\mathrm{HGF} / \mathrm{c}-\mathrm{Met}$ signaling. The increase in TGF- $\beta 1$ expression is closely correlated with oxalate-induced tubular epithelial cell injury and the development of nephrolithiasis. One of the proposed mechanisms is the antagonistic interaction between PPAR- $\gamma$ and TGF- $\beta$ signaling. PPAR- $\gamma$ agonists have been reported to exert antifibrotic effects in human proximal tubule cells and to reduce high glucose levels by attenuating TGF- $\beta 1$ [31]. PPAR- $\gamma$ can inhibit the phosphorylation of Smad 2 and Smad 3 and repress the TGF- $\beta 1$ signaling pathway [33]. PPAR- $\gamma$ activation by its agonists, such as RSG, PGZ, and 15d-PGJ2, or genetic PPAR- $\gamma$ overexpression prevented the induction of ROS induced by TGF- $\beta 1$ [31]. However, some cytokines and chemokines have been shown to regulate PPAR- $\gamma$ expression. TGF- $\beta 1$ reduces PPAR- $\gamma$ expression in fibroblasts and hepatic stellate cells [34]. Moreover, TGF- $\beta 1$-induced ROS were reported to suppress PPAR- $\gamma$ expression and activity by enhancing oxidative stress damage, and activated PPAR- $\gamma$, in turn, protects renal tubular cells by inhibiting the oxidative response [35]. Consistent with these previous findings, in our study, rat tissues exhibited significantly enhanced expression and activity of TGF- $\beta 1$, Smad2, and Smad3 after 7 days of treatment with EG, but TGF- $\beta 1$ overexpression related to renal injury induced by hyperoxaluria was prevented by RSG injection in the rat model. Similar results were observed in vitro. These suppressive effects of RSG on TGF- $\beta 1$ in the kidneys were reversed by GW9662. Our results clearly illustrated 
the antagonistic interaction between PPAR- $\gamma$ and the TGF$\beta 1 / \mathrm{ROS}$ axis in renal tubular cells.

HGF, as a heparin-binding disulfide-linked heterodimer, is a potent antifibrotic cytokine and plays an antifibrotic role in a variety of organs [18]. HGF and its specific receptor c-Met have multiple biological functions in renal tubular cells, such as antifibrotic and antioxidation effects [36]. HGF exerts remarkable antioxidative effects by promoting ROS scavenging and reducing ROS production and accumulation in rat mesangial cells [37]. Since HGF is an endogenous secreted cytokine, the best way to increase HGF expression in vivo is to activate its upstream molecules and then upregulate its expression. However, the detailed mechanism of HGF secretion from renal tubular cells remains unclear. Recent studies revealed that HGF acts as a downstream effector of PPAR- $\gamma$ agonists. Transfection studies revealed that 15d-PGJ2 (a PPAR- $\gamma$ agonist) stimulated the activity of the HGF gene promoter due to the presence of a novel PPRE, and PPAR- $\gamma$ agonists promoted not only HGF expression but also c-Met phosphorylation in mesangial cells [18]. The PPAR- $\gamma$ agonists telmisartan and irbesartan play an antirenal fibrosis role by increasing HGF production and secretion [27, 38]. Recently, the protective effect of PPAR- $\gamma$ agonists was considered partly to be the result of increasing HGF expression [39]. Therefore, we postulate that the PPAR- $\gamma$-HGF/c-Met axis also exists in tubular cells. In this study, after oxalate treatment, we found a decrease in HGF and c-Met expression in renal tubular cells following repression of PPAR- $\gamma$. These phenomena could be reversed by the addition of RSG. Moreover, treatment of MDCK cells with GW9662 alone decreased HGF and c-Met expression as well as c-Met phosphorylation. Combined with previous research by others, our results demonstrate that a constitutively activated PPAR- $\gamma$-HGF/c-Met axis exists in tubular cells and exerts nephroprotective effects. Next, we found that GW9662 abolished RSG-induced HGF/c-Met expression in response to oxalate, and the protective effect of RSG could be eliminated by a c-Met inhibitor (PHA665752) or siRNA silencing of HGF. These results indicated that the nephroprotective role of RSG largely depends on the PPAR- $\gamma$-HGF/c-Met axis.

\section{Conclusions}

In summary, we suggest that oxalate inhibits PPAR- $\gamma$ expression and activity via the TGF- $\beta 1$-ROS pathway in renal tubular cells and that enhanced TGF- $\beta 1$ expression is a result of PPAR $-\gamma$ reduction. Furthermore, the repression of PPAR- $\gamma$ also downregulates the HGF/c-Met pathway. The imbalance between TGF- $\beta 1$ and HGF/c-Met leads to the accumulation of ROS and related protein damage, which becomes the initial event in the development of nephrolithiasis. PPAR- $\gamma$ agonists not only inhibit TGF- $\beta 1$ signaling but also enhance the HGF/c-Met pathway in tubular cells exposed to oxalate and exert antioxidant and nephroprotective effects. Therefore, activation of PPAR- $\gamma$ may be a potent target for protecting tubular cells from hyperoxaluria-induced oxidative injury and inhibiting $\mathrm{CaOx}$ crystal deposition. We believe that new PPAR- $\gamma$ agonists with fewer side effects that emerge in the future may be a therapy for nephrolithiasis.

\section{Data Availability}

The data used to support the findings of this study are available from the corresponding author upon request.

\section{Conflicts of Interest}

The authors declare that they have no competing interests.

\section{Authors' Contributions}

Ya-Dong Liu and Shi-Liang Yu contributed equally to this work and should be considered co-first authors.

\section{Acknowledgments}

This work was supported by the innovation project of Harbin Medical University (YJSKYCX2018-35HYD) and the National Natural Science Foundation of China (NFSC, No. 81370803).

\section{Supplementary Materials}

Table S1: the siRNA sequences for the HGF gene. Figure S1: the expression of related proteins in vitro is indicated by a graphical representation $(\mathrm{A}-\mathrm{H})$. The expression level of PPAR- $\gamma$ in the cytoplasm and nucleus in vitro is illustrated by a graphical representation (I). Figure S2: the expression of proteins in vivo is illustrated by a graphical representation $(\mathrm{A}-\mathrm{H})$. The expression level of PPAR- $\gamma$ in the cytoplasm and nucleus in vivo is illustrated by a graphical representation (I). Figure S3: black-stained crystals in the whole cross-section were observed in original pictures of kidney Pizzolato staining under a 10-fold magnification. Figure S4: histopathological and morphological changes of the kidney were observed in different groups under a 200-fold magnification. (Supplementary Materials)

\section{References}

[1] P. Cunningham, H. Noble, A. K. Al-Modhefer, and I. Walsh, "Kidney stones: pathophysiology, diagnosis and management," British Journal of Nursing, vol. 25, no. 20, pp. 11121116, 2016.

[2] L. Yu, X. Gan, X. Liu, and R. An, "Calcium oxalate crystals induces tight junction disruption in distal renal tubular epithelial cells by activating ROS/Akt/p38 MAPK signaling pathway," Renal Failure, vol. 39, no. 1, pp. 440-451, 2017.

[3] S. L. Yu, X. G. Gan, J. M. Huang et al., "Oxalate impairs aminophospholipid translocase activity in renal epithelial cells via oxidative stress: implications for calcium oxalate urolithiasis," Journal of Urology, vol. 186, no. 3, pp. 1114-1120, 2011.

[4] B. Qin, Q. Wang, Y. Lu et al., "Losartan ameliorates calcium oxalate-induced elevation of stone-related proteins in renal tubular cells by inhibiting NADPH oxidase and oxidative stress," Oxidative Medicine and Cellular Longevity, vol. 2018, Article ID 1271864, 12 pages, 2018.

[5] Y. Chen, X. Feng, X. Hu et al., "Dexmedetomidine ameliorates acute stress-induced kidney injury by attenuating oxidative 
stress and apoptosis through inhibition of the ROS/JNK signaling pathway," Oxidative Medicine and Cellular Longevity, vol. 2018, Article ID 4035310, 12 pages, 2018.

[6] J. B. Koo, M.-O. Nam, Y. Jung et al., “Anti-fibrogenic effect of PPAR- $\gamma$ agonists in human intestinal myofibroblasts," BMC Gastroenterology, vol. 17, no. 1, p. 73, 2017.

[7] T. Kawai, T. Masaki, S. Doi et al., "PPAR- $\gamma$ agonist attenuates renal interstitial fibrosis and inflammation through reduction of TGF- $\beta$," Laboratory Investigation, vol. 89, no. 1, pp. 47-58, 2009.

[8] T. Yang and S. Soodvilai, "Renal and vascular mechanisms of thiazolidinedione-induced fluid retention," PPAR Research, vol. 2008, Article ID 943614, 8 pages, 2008.

[9] Z.-N. Zhu, Y.-F. Jiang, and T. Ding, "Risk of fracture with thiazolidinediones: an updated meta-analysis of randomized clinical trials," Bone, vol. 68, pp. 115-123, 2014.

[10] A. Sugawara, A. Uruno, M. Kudo, K. Matsuda, C. W. Yang, and S. Ito, "Effects of PPAR $\gamma$ on hypertension, atherosclerosis, and chronic kidney disease," Endocrine Journal, vol. 57, no. 10, pp. 847-852, 2010.

[11] S. Li, Y. Lan, W. Wu et al., "Peroxisome proliferator-activated receptor $\gamma$ modulates renal crystal retention associated with high oxalate concentration by regulating tubular epithelial cellular transdifferentiation," Journal of Cellular Physiology, vol. 234, no. 3, pp. 2837-2850, 2019.

[12] X.-H. Yang, P. Li, Y.-L. Yin et al., "Rosiglitazone via PPAR $\gamma$ dependent suppression of oxidative stress attenuates endothelial dysfunction in rats fed homocysteine thiolactone," Journal of Cellular and Molecular Medicine, vol. 19, no. 4, pp. 826-835, 2015.

[13] G. J. Ko, Y. S. Kang, S. Y. Han et al., "Pioglitazone attenuates diabetic nephropathy through an anti-inflammatory mechanism in type 2 diabetic rats," Nephrology Dialysis Transplantation, vol. 23, no. 9, pp. 2750-2760, 2008.

[14] R. Agarwal, "Anti-inflammatory effects of short-term pioglitazone therapy in men with advanced diabetic nephropathy," American Journal of Physiology-Renal Physiology, vol. 290, no. 3, pp. F600-F605, 2006.

[15] C.-W. Tung, C. Ho, Y.-C. Hsu, S.-C. Huang, Y.-H. Shih, and C.-L. Lin, "MicroRNA-29a attenuates diabetic glomerular injury through modulating cannabinoid receptor 1 signaling," Molecules, vol. 24, no. 2, p. 264, 2019.

[16] H. Y. Lan and A. C.-K. Chung, "TGF- $\beta /$ Smad signaling in kidney disease," Seminars in Nephrology, vol. 32, no. 3, pp. 236-243, 2012.

[17] T. Rashed, M. Menon, and S. Thamilselvan, "Molecular mechanism of oxalate-induced free radical production and glutathione redox imbalance in renal epithelial cells: effect of antioxidants," American Journal of Nephrology, vol. 24, no. 5, pp. 557-568, 2004.

[18] Y. Li, X. Wen, B. C. Spataro, K. Hu, C. Dai, and Y. Liu, "Hepatocyte growth factor is a downstream effector that mediates the antifibrotic action of peroxisome proliferator-activated receptor- $\gamma$ agonists," Journal of the American Society of Nephrology, vol. 17, no. 1, pp. 54-65, 2006.

[19] K. H. Lee and J.-R. Kim, "Reactive oxygen species regulate the generation of urokinase plasminogen activator in human hepatoma cells via MAPK pathways after treatment with hepatocyte growth factor," Experimental and Molecular Medicine, vol. 41, no. 3, pp. 180-188, 2009.
[20] R. Imamura and K. Matsumoto, "Hepatocyte growth factor in physiology and infectious diseases," Cytokine, vol. 98, pp. 97-106, 2017.

[21] A. Vallée and Y. Lecarpentier, "Crosstalk between peroxisome proliferator-activated receptor gamma and the canonical $\mathrm{WNT} / \beta$-catenin pathway in chronic inflammation and oxidative stress during carcinogenesis," Frontiers in Immunology, vol. 9, p. 745, 2018.

[22] A. Song, G. Wu, H. Hang, and L. Wang, "Rosiglitazone pretreatment influences thrombin-induced anti-oxidative action via activating NQO1 and $\gamma$-GCS in rat microglial cells," Neurological Research, vol. 40, no. 2, pp. 139-145, 2017.

[23] M. A. Valentovic, J. G. Ball, J. Mike Brown et al., "Resveratrol attenuates cisplatin renal cortical cytotoxicity by modifying oxidative stress," Toxicology In Vitro, vol. 28, no. 2, pp. 248257, 2014.

[24] Y. Wang, S. Zhang, J. Liu, B. Fang, J. Yao, and B. Cheng, "Matrine inhibits the invasive and migratory properties of human hepatocellular carcinoma by regulating epithelialmesenchymal transition," Molecular Medicine Reports, vol. 18, no. 1, pp. 911-919, 2018.

[25] K. Taguchi, A. Okada, S. Hamamoto et al., "Differential roles of peroxisome proliferator-activated receptor- $\alpha$ and receptor$\gamma$ on renal crystal formation in hyperoxaluric rodents," PPAR Research, vol. 2016, Article ID 9605890, 11 pages, 2016.

[26] T.-B. Zhou, G. P. C. Drummen, Z.-P. Jiang, Y.-B. Long, and Y.-H. Qin, "Association of peroxisome proliferator-activated receptors/retinoic acid receptors with renal diseases," Journal of Receptors and Signal Transduction, vol. 33, no. 6, pp. 349-352, 2013.

[27] G. S. Dhaunsi, M. H. M. Yousif, S. Akhtar, M. C. Chappell, D. I. Diz, and I. F. Benter, "Angiotensin-(1-7) prevents diabetes-induced attenuation in PPAR- $\gamma$ and catalase activities," European Journal of Pharmacology, vol. 638, no. 1-3, pp. 108-114, 2010.

[28] A. P. Lakshmanan, K. Watanabe, R. A. Thandavarayan et al., "Telmisartan attenuates oxidative stress and renal fibrosis in streptozotocin induced diabetic mice with the alteration of angiotensin-(1-7) mas receptor expression associated with its PPAR- $\gamma$ agonist action," Free Radical Research, vol. 45, no. 5, pp. 575-584, 2011.

[29] S. Diano, Z.-W. Liu, J. K. Jeong et al., "Peroxisome proliferation-associated control of reactive oxygen species sets melanocortin tone and feeding in diet-induced obesity," Nature Medicine, vol. 17, no. 9, pp. 1121-1127, 2011.

[30] X. Yang, H. Ding, Z. Qin et al., "Metformin prevents renal stone formation through an antioxidant mechanism in Vitro and in vivo," Oxidative medicine and cellular longevity, vol. 2016, Article ID 4156075, 10 pages, 2016.

[31] C. R. Jesse, C. F. Bortolatto, E. A. Wilhelm, S. S. Roman, M. Prigol, and C. W. Nogueira, "The peroxisome proliferator-activated receptor- $\gamma$ agonist pioglitazone protects against cisplatin-induced renal damage in mice," Journal of Applied Toxicology, vol. 34, no. 1, pp. 25-32, 2014.

[32] X. Wang, Z. Wang, J. Z. Liu et al., "Double antioxidant activities of rosiglitazone against high glucose-induced oxidative stress in hepatocyte," Toxicology in Vitro, vol. 25, no. 4, pp. 839-847, 2011.

[33] G. Y. Zhang, T. Cheng, M. H. Zheng et al., "Peroxisome proliferator-activated receptor- $\gamma$ (PPAR- $\gamma$ ) agonist inhibits transforming growth factor-betal and matrix production in 
human dermal fibroblasts," Journal of Plastic, Reconstructive \& Aesthetic Surgery, vol. 63, no. 7, pp. 1209-1216, 2010.

[34] J. Wei, S. Bhattacharyya, M. Jain, and J. Varga, "Regulation of matrix remodeling by peroxisome proliferator-activated receptor- $\gamma$ : a novel link between metabolism and fibrogenesis," The Open Rheumatology Journal, vol. 6, no. 1, pp. 103-115, 2012.

[35] A. Tabassum and T. Mahboob, "Role of peroxisome proliferator-activated receptor-gamma activation on visfatin, advanced glycation end products, and renal oxidative stress in obesityinduced type 2 diabetes mellitus," Human \& Experimental Toxicology, vol. 37, no. 11, pp. 1187-1198, 2018.

[36] S. Takeda, H. Liu, S. Sasagawa et al., "HGF-MET signals via the MLL-ETS2 complex in hepatocellular carcinoma," The Journal of Clinical Investigation, vol. 123, no. 7, pp. 3154-3165, 2013.

[37] H. Li, T. Jiang, Y. Lin, Z. Zhao, and N. Zhang, "HGF protects rat mesangial cells from high-glucose-mediated oxidative stress," American Journal of Nephrology, vol. 26, no. 5, pp. 519-530, 2006.

[38] S. Afzal, M. A. Sattar, E. J. Johns et al., "Interaction between irbesartan, peroxisome proliferator-activated receptor $(\operatorname{PPAR}-\gamma)$, and adiponectin in the regulation of blood pressure and renal function in spontaneously hypertensive rats," Journal of Physiology and Biochemistry, vol. 72, no. 4, pp. 593-604, 2016.

[39] M. de Souza Durão, C. V. Razvickas, E. A. P. Gonçalves et al., "The role of growth factors on renal tubular cells submitted to hypoxia and deprived of glucose," Renal Failure, vol. 25, no. 3, pp. 341-353, 2003. 


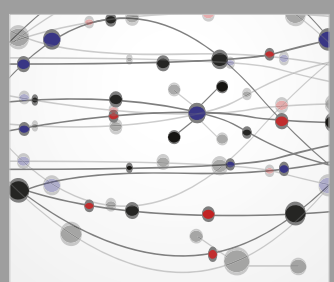

The Scientific World Journal
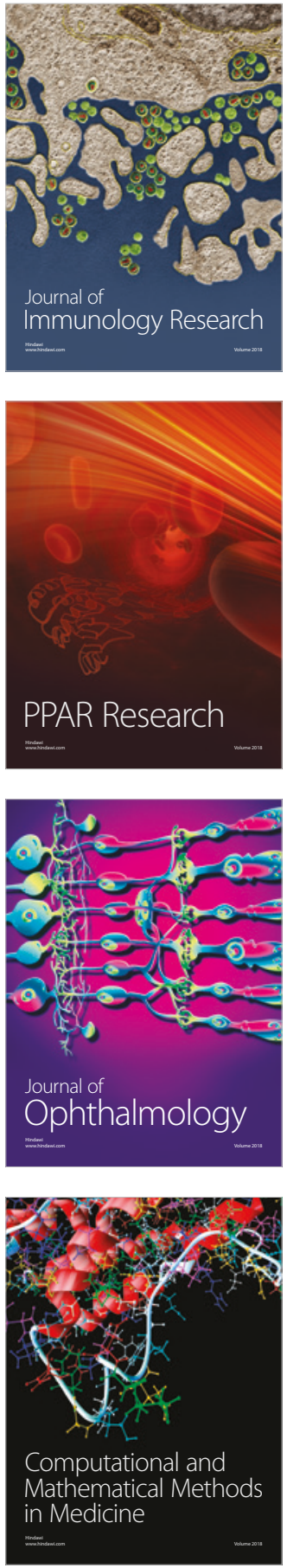

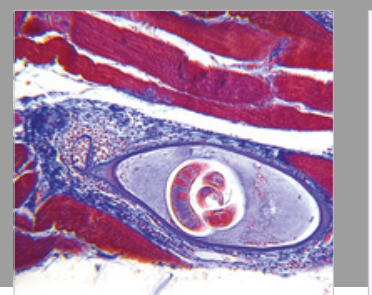

Gastroenterology Research and Practice

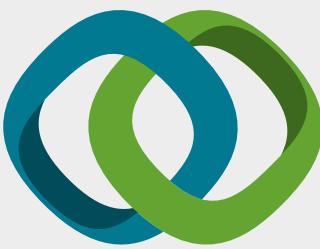

\section{Hindawi}

Submit your manuscripts at

www.hindawi.com
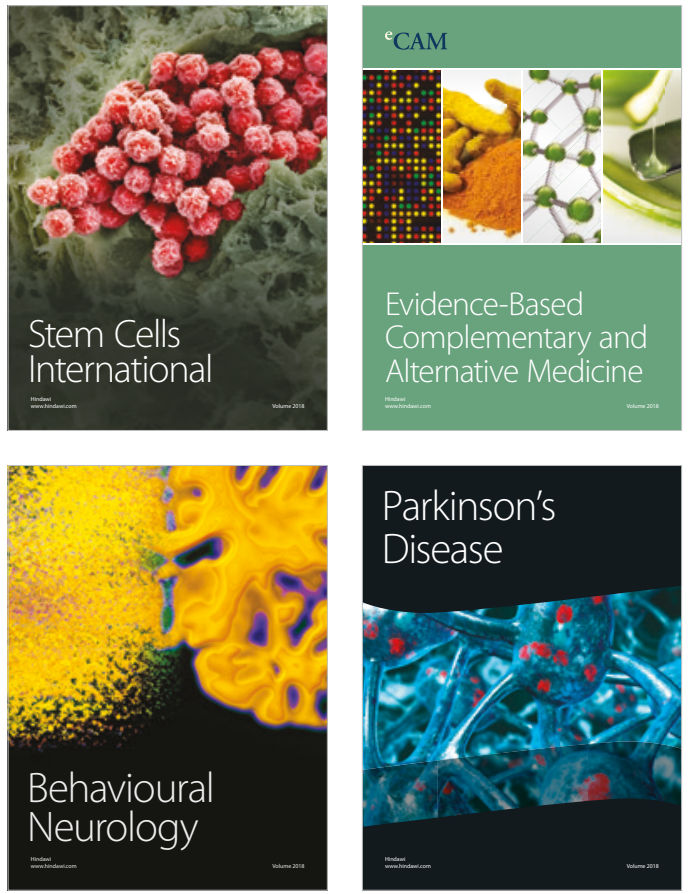

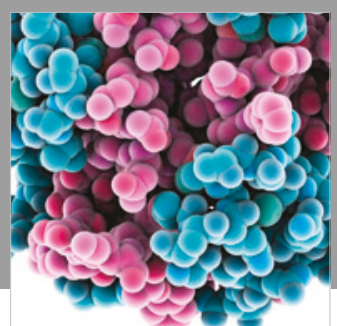

ournal of

Diabetes Research

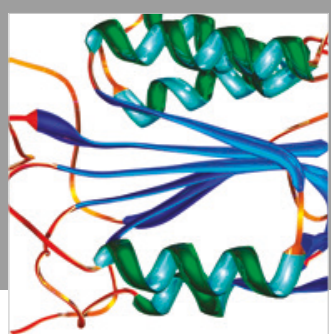

Disease Markers
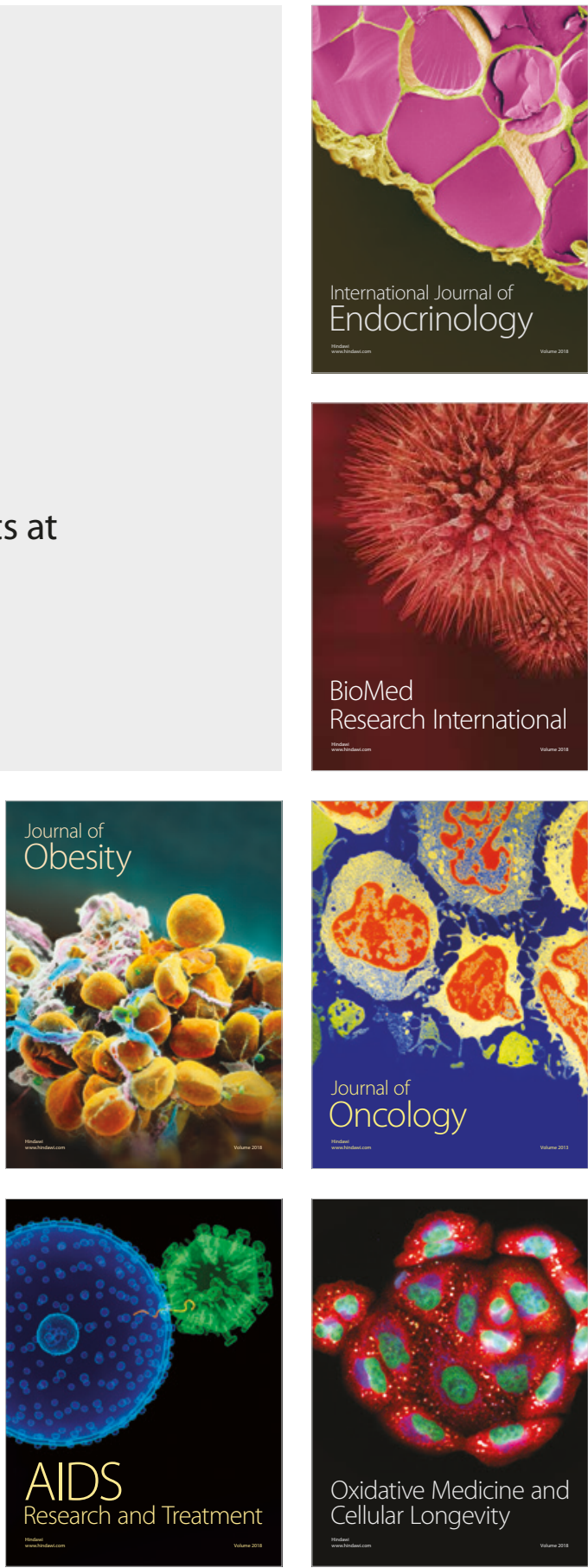